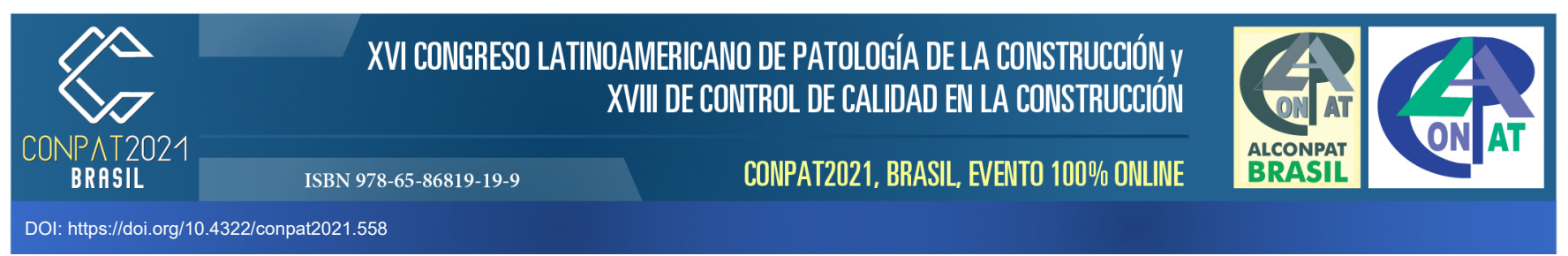

\title{
Inspeção Rotineira na Ponte Sobre o Córrego Mutuca no Município de Gurupi - TO
}

\author{
F. M. David ${ }^{1}$, M. M. de Souza ${ }^{1}$, F. A. S. Fernandes ${ }^{1}$, D. F. A. dos $\operatorname{Santos}^{1 *}$ \\ *Autor de Contacto: douglasasantos@unirg.edu.br \\ ${ }^{1}$ Faculdade de Engenharia Civil, Universidade de Gurupi, Gurupi, Brasil
}

\begin{abstract}
RESUMO
As estruturas em concreto armado são suscetíveis ao aparecimento de anomalias ao longo de sua vida útil. Objetiva-se com este trabalho a verificação de manifestações patológicas através de inspeção visual, tendente para a ponte de Gurupi-Tocantins, situada sobre o córrego Mutuca na BR $153, \mathrm{~km} \mathrm{671,} \mathrm{no} \mathrm{Brasil.} \mathrm{A} \mathrm{ponte} \mathrm{apresentou} \mathrm{problemáticas} \mathrm{como,} \mathrm{fissura} \mathrm{no} \mathrm{pavimento,} \mathrm{trinca} \mathrm{na}$ face inferior da laje, reação álcali agregado, etc. As inspeções seguiram as diretrizes da NBR 9452 (2019) e o manual de inspeção de Pontes Rodoviárias (DNIT - 2004). Verificou-se que a ponte apresenta boas condições, entretanto, devido recebe uma nota 3 , precisa ser monitorada para não diminuir sua vida útil.
\end{abstract}

Palavras chaves: Inspeção; Pontes; Concreto Armado. 


\title{
RESUMEN
}

Las estructuras de hormigón armado son susceptibles a la aparición de anomalías a lo largo de su vida útil. El objetivo de este trabajo es verificar las manifestaciones patológicas mediante inspección visual, tendiendo hacia el puente Gurupi-Tocantins, ubicado sobre el arroyo Mutuca en la BR 153, km 671, en Brasil. El puente presentó problemas como grietas en el pavimento, grietas en la parte inferior de la losa, reacción alcalina agregada, etc. Las inspecciones siguieron las pautas de NBR 9452 (2019) y el manual de inspección de puentes de carretera (DNIT - 2004). Se encontró que el puente está en buenas condiciones, sin embargo, como recibe una calificación de 3 , es necesario monitorearlo para no reducir su vida útil.

Palabras clave: Inspección; Puentes; Hormigón Armado.

\begin{abstract}
Reinforced concrete structures are susceptible to the appearance of pathologies throughout their useful life. The aim of this work is to study its pathologies through research in the literature and visual inspection, tending towards the Gurupi-Tocantins bridge, located over the Mutuca stream on BR 153, Km 671. It presents the problems such as, fissure on the pavement, cracking on the underside of the slab, aggregated alkali reaction, etc. The inspections followed the guidelines of NBR 9452: 2019 and the inspection manual for Highway Bridges (DNIT - 2004). It was found that the bridge is in good condition, however, as it receives a grade of 3 , it needs to be monitored so as not to reduce its useful life.
\end{abstract}

Keywords: Inspection; Bridges; Reinforced Concrete.

\section{INTRODUÇÃO}

Os principias requisitos ao projetar uma ponte e atender um bom desempenho são: funcionalidade, segurança, estética, economia e durabilidade. E suas principais problemáticas estão ligadas erros de projeto e execução, falta de inspeção, gestão e manutenção.

Muitas pontes foram projetadas com base em normativas vigentes da época que consideravam cargas móveis diferentes das atuais, além de fatores de impacto, tipos de ações, etc. Outro ponto a ser levado em consideração é a falta de gestão dessas Obras de Artes Especiais (OAEs) durante sua vida útil. As inspeções devem ser conduzidas de forma organizada e sistemática, além de ser feito por profissionais competentes e habilitados.

Portanto, este trabalho tem por objetivo identificar as manifestações patológicas presentes na ponte sobre o córrego Mutuca. Ela passou a ser um viaduto por questões de ampliação de faixas e crescimento da população em seu entorno. A inspeção visual e registros fotográficos seguiram as diretrizes da (ABNT NBR 9452, 2019) e o manual de inspeção de Pontes Rodoviárias (DNIT, 2004).

\section{METODOLOGIA}

O trabalho trata-se de um estudo qualitativo, utilizando critérios baseados em recomendações e normativas, sendo estas, a (ABNT NBR 9452, 2019) e o manual de inspeções rodoviárias do (DNIT, 2004). Foram verificados pequenos danos a OAE através de inspeções visuais realizadas 
nos dias 20, 24 e 28 de abril de 2021, na ponte localizada na BR 153, sobre o antigo córrego Mutuca da cidade de Gurupi - TO (ver Figura 1 e 2). Esta ponte possui uma extensão de 36,00 metros, seu sistema estrutural é de pontes em vigas. O fluxo de trânsito é considerável, devido ser uma via de acesso ao centro da cidade e saída de uma BR.

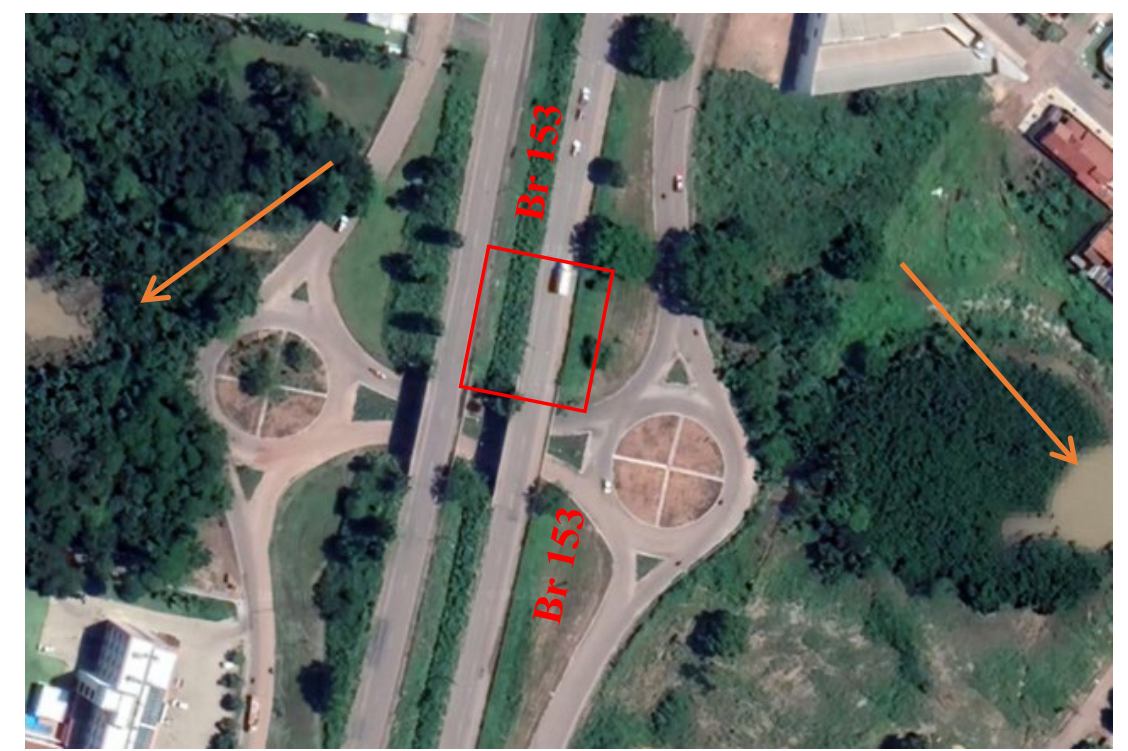

Figura 1. Localização da ponte e cursor d'água (Google Earth, 2021)

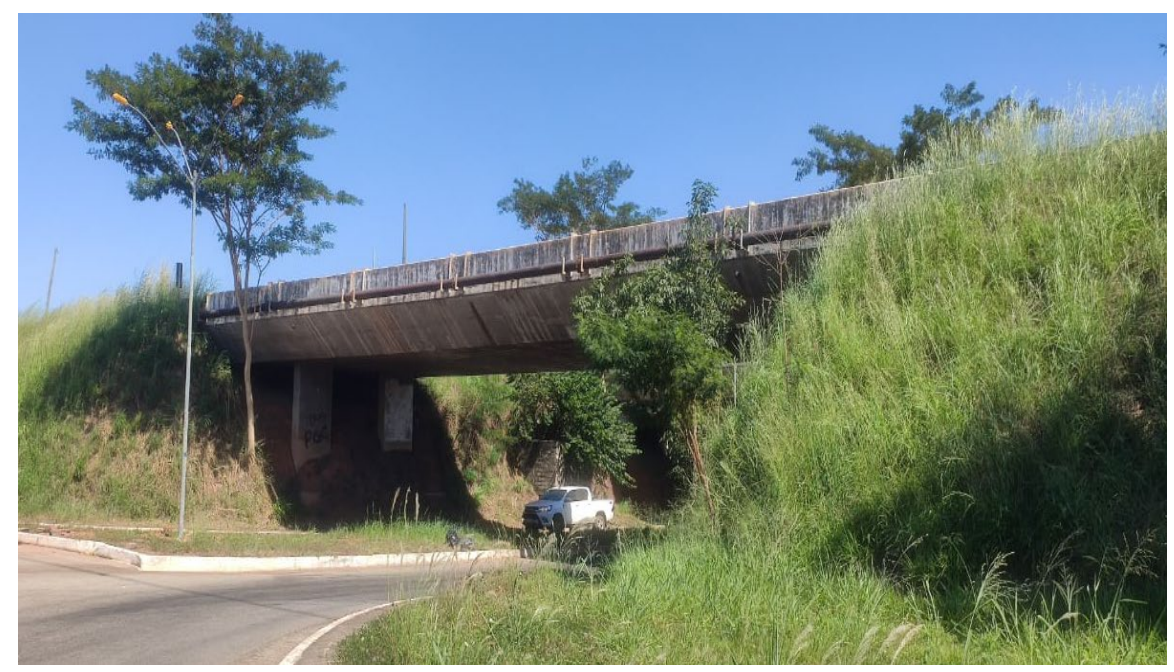

Figura 2. Vista Lateral da Ponte.

Para o levantamento da situação da ponte foi utilizado os modelos de ficha de inspeção rotineira da (ABNT NBR 9452, 2019). Este modelo é dividido em 3 partes, sendo a parte 1 dados cadastrais, como, identificação e localização, históricos das inspeções, descrição das intervenções executadas ou em andamento. Na parte 2, registros destas manifestações patológicas, de forma descritiva. E por fim, na parte 3 determinações da classificação da OAE e os registros fotográficos realizados na inspeção.

Diante da inspeção visual e levantamento de dados histórico da ponte, notou-se que a ponte de Gurupi localizada na BR 153, km 671 apresenta algumas manifestações patológicas e reparos preventivos. Os dados obtidos na ficha de inspeção e registro fotográfico estão descritos nos tópicos abaixo e em anexo. 


\subsection{Notas de Classificação}

A classificação de uma obra de arte consiste na atribuição de uma nota de avaliação, variando de 1 a 5, correlacionada à sua condição, podendo ser excelente (5), boa (4), regular (3), ruim (2) ou crítica (1) (ABNT NBR 9452, 2019). A classificação deve seguir o estabelecido na Tabela 1.

Tabela 1. Classificação da condição da obra de arte segundo os parâmetros estrutural, funcional e dedurabilidade (ABNT NBR 9452, 2019).

\begin{tabular}{|c|c|c|c|c|}
\hline \begin{tabular}{c|} 
Nota de \\
Classificação
\end{tabular} & Condição & Caracterização Estrutural & $\begin{array}{c}\text { Caracterização } \\
\text { Funcional }\end{array}$ & $\begin{array}{c}\text { Caracterização de } \\
\text { Durabilidade }\end{array}$ \\
\hline 5 & Excelente & $\begin{array}{l}\text { A estrutura apresenta-se } \\
\text { em condições } \\
\text { satisfatórias, } \\
\text { apresentando defeitos } \\
\text { irrelevantes e isolados. }\end{array}$ & $\begin{array}{c}\text { A obra de arte apresenta } \\
\text { segurança e conforto aos } \\
\text { usuários. }\end{array}$ & $\begin{array}{c}\text { A obra de arte está } \\
\text { em perfeitas } \\
\text { condições, } \\
\text { devendo ser prevista } \\
\text { manutenção de } \\
\text { rotina. }\end{array}$ \\
\hline 4 & Boa & $\begin{array}{l}\text { A estrutura apresenta } \\
\text { danos pequenos e em } \\
\text { áreas isoladas, sem } \\
\text { comprometer a } \\
\text { segurança estrutural. }\end{array}$ & $\begin{array}{c}\text { A obra de arte apresenta } \\
\text { pequenos danos que não } \\
\text { chegam a causar perda } \\
\text { redução } \\
\text { significativa de } \\
\text { desempenho, } \\
\text { desconforto ou } \\
\text { insegurança ao usuário. }\end{array}$ & $\begin{array}{c}\text { A obra de arte } \\
\text { apresenta pequenas e } \\
\text { poucas } \\
\text { anomalias que } \\
\text { comprometam sua } \\
\text { vida } \\
\text { útil. Estrutura em } \\
\text { região de baixa } \\
\text { agressividade } \\
\text { ambiental. }\end{array}$ \\
\hline 3 & Regular & $\begin{array}{l}\text { Há danos que podem vir } \\
\text { a gerar alguma } \\
\text { deficiência estrutural, } \\
\text { mas não há sinais de } \\
\text { comprometimento da } \\
\text { estabilidade da obra. } \\
\text { Recomenda-se } \\
\text { acompanhamento dos } \\
\text { problemas. Intervenções } \\
\text { podem ser necessárias a } \\
\text { médio prazo. }\end{array}$ & $\begin{array}{l}\text { A obra de arte apresenta } \\
\text { desconforto ao usuário, } \\
\text { com defeitos que } \\
\text { requerem ações de } \\
\text { médio prazo. }\end{array}$ & $\begin{array}{c}\text { A obra de arte } \\
\text { apresenta pequenas e } \\
\text { poucas } \\
\text { anomalias, que } \\
\text { comprometam sua } \\
\text { vida útil, em regiões } \\
\text { de moderada a alta } \\
\text { agressividade } \\
\text { ambiental ou } \\
\text { apresenta moderadas } \\
\text { à muitas anomalias, } \\
\text { mas a estrutura está } \\
\text { em região de baixa } \\
\text { agressividade } \\
\text { ambiental. }\end{array}$ \\
\hline 2 & Ruim & $\begin{array}{c}\text { Há danos que } \\
\text { comprometem a } \\
\text { segurança da estrutura, } \\
\text { porém, sem risco } \\
\text { iminente. Sua evolução } \\
\text { pode levar ao colapso } \\
\text { estrutural. A obra de } \\
\text { arte necessita de } \\
\text { intervenções } \\
\text { significativa a curto } \\
\text { prazo. }\end{array}$ & $\begin{array}{l}\text { A obra de arte com } \\
\text { funcionalidade } \\
\text { visivelmente } \\
\text { comprometida, com } \\
\text { risco de segurança ao } \\
\text { usuário, requerendo } \\
\text { intervenções de curto } \\
\text { prazo. }\end{array}$ & $\begin{array}{c}\text { A obra de arte } \\
\text { apresenta } \\
\text { anomalias moderadas } \\
\text { a } \\
\text { abundantes, que } \\
\text { comprometam sua } \\
\text { vida } \\
\text { útil, em regiões de } \\
\text { alta } \\
\text { agressividade } \\
\text { ambiental. }\end{array}$ \\
\hline
\end{tabular}




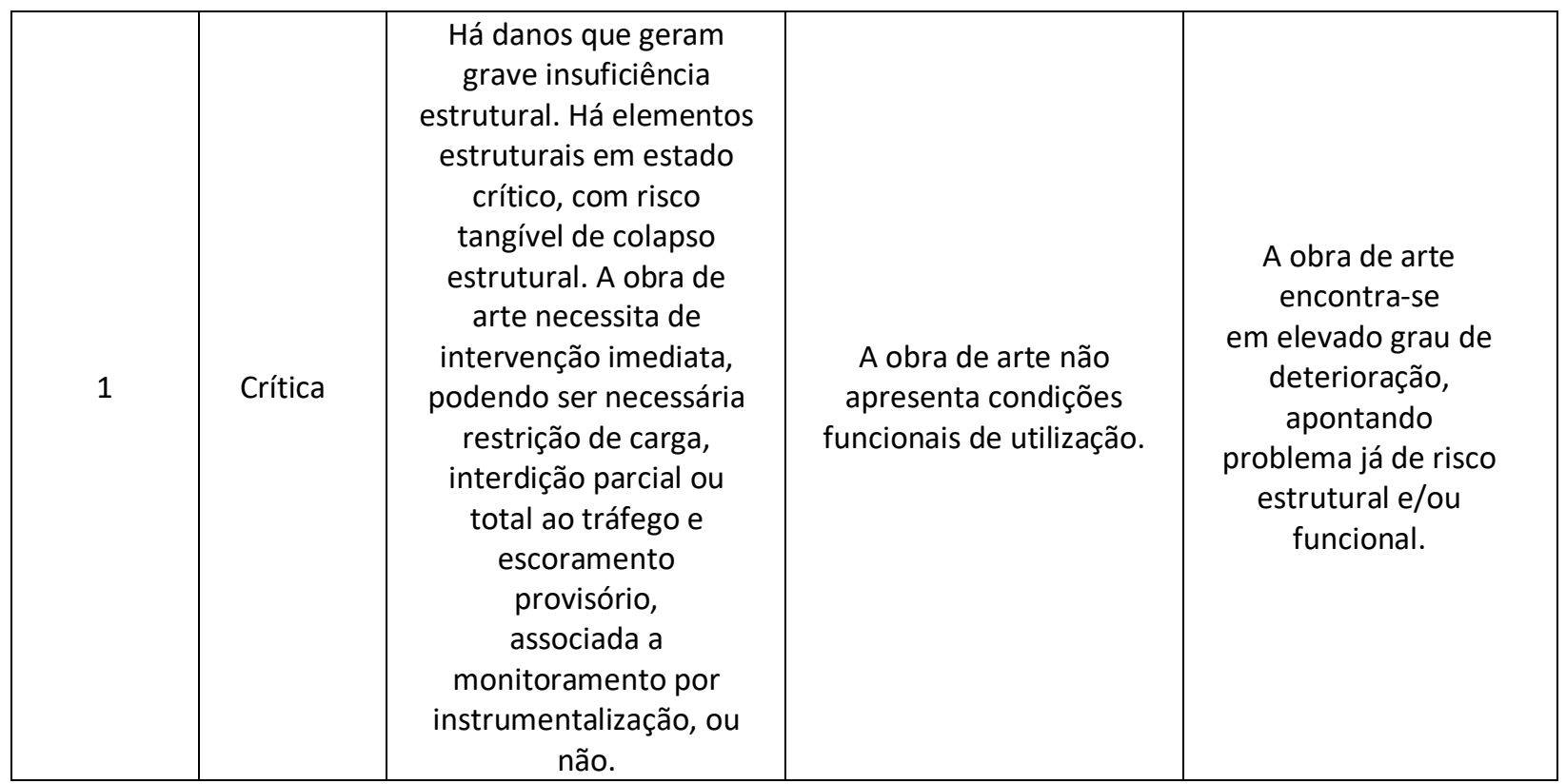

\subsection{Ficha de Inspeção Rotineira}

Como descrito anteriormente a ficha de inspeção é dividida em 3 partes, sendo a parte 1 composta por dados cadastrais, conforme apresentado na Tabela 2. Nesta tabela pode-se notar que são necessários informações de dados históricos da inspeção.

Tabela 2. Modelo de ficha de inspeção rotineira parte 1 (ABNT NBR 9452, 2019).

\begin{tabular}{|c|c|c|}
\hline № & \multicolumn{2}{|c|}{ Ficha de Inspeção Rotineira } \\
\hline 1 & Inspeção Rotineira(ano):2021 & Código da obra de arte: 0020201 \\
\hline 2 & $\begin{array}{l}\text { Jurisdição (Órgão, Concessão ou outro): } \\
\text { Federal }\end{array}$ & Data de Inspeção: 28 de abril \\
\hline & \multicolumn{2}{|c|}{ Parte I - Cadastro } \\
\hline & \multicolumn{2}{|c|}{ A - Identificação e localização } \\
\hline 3 & Via e Município: BR 153 & Sentido: Palmas \\
\hline 4 & Obra: Ponte sobre o córrego Mutuca & $\begin{array}{l}\text { Localização (km e coordenadas geográficas): } \\
\text { Km671 }\end{array}$ \\
\hline & \multicolumn{2}{|c|}{ B - Histórico das Inspeções } \\
\hline 5 & Inicial: Nada consta & Última Rotineira: Nada consta \\
\hline 6 & Especial: Nada consta & \\
\hline & \multicolumn{2}{|c|}{ C - Descrição das intervenções executadas ou em andamento } \\
\hline 7 & Reparos: Nada consta & Material: Nada consta \\
\hline 8 & Alargamentos: Nada consta & \\
\hline 9 & Reforços: Nada consta & \\
\hline
\end{tabular}

A Tabela 3 apresenta o registro de manifestações patológicas encontradas nos componentes da ponte. Dentre os apresentados pode-se verificar problemas na superestrutura, especificamente no tabuleiro, como, problemas de degradação, acúmulo de pontos de umidade devido a ineficiência da drenagem. 
Os pilares com problemas de calcinação, ocasionado por erro na concretagem. Da mesma forma, pode-se encontrar problemas em outros componentes da ponte que foram descritos melhor na tabela 3.

Tabela 3. Modelo de ficha de inspeção rotineira parte 2 (ABNT NBR 9452, 2019).

\begin{tabular}{|l|l|}
\hline No & \multicolumn{1}{|c|}{ Aarte II - Registro de manifestações patológicas } \\
\hline 10 & Superestrutura: \\
\hline 11 & Mesoestrutura: \\
\hline 12 & Infraestrutura: Calcinação do Concreto \\
\hline 13 & Aparelhos de Apoio: \\
\hline 14 & Juntas de Dilatação: Trincas no encontro do pavimento \\
\hline 15 & Encontros: \\
\hline 16 & Outros elementos: \\
\hline & \\
\hline 17 & Pavimento: Fissuras no encontro da ponte com o pavimento \\
\hline 18 & Acostamento e Refúgio: \\
\hline 19 & Drenagem: \\
\hline 20 & Impermeabilização: \\
\hline 21 & Guarda-corpos: \\
\hline 22 & Barreira de Concreto/ Defensa Metálica: \\
\hline & \\
\hline 23 & Taludes: \\
\hline 24 & C - Outros Elementos \\
\hline 25 & Sinalização: \\
\hline 26 & Gabarito: \\
\hline 27 & Proteção de Pilares: \\
\hline & \\
\hline 28 & \\
\hline & \\
\hline 29 & D - Informações Complementares \\
\hline
\end{tabular}

A parte 3 trata-se do registro fotográfico e a classificação dada pelo inspetor a obra vistoriada, a Tabela 4 se encontra em anexo e suas manifestações patológicas são descritas nos tópicos abaixo. Esta ponte, devido a problemas apresentados a alguns elementos estruturais, obteve classificação igual a 4, sendo considerada pela (ABNT NBR 9452, 2019), como uma ponte de classificação boa. A classificação sempre será a menor nota obtida entre os elementos e parâmetros. 


\section{RESULTADOS}

\subsection{Fissuras}

Segundo a norma do (DNIT 090, 2006) as fissuras são classificadas como causas físicas da deterioração do concreto. Foram observadas trincas e fissuras em praticamente toda a estrutura da ponte; essas fissuras podem ocorrer em consequência da fragilidade do concreto que continuamente está relacionado a fatores ambientais, como chuva causando excesso de umidade, insolação causando retração no concreto; por este motivo o concreto recebe uma tensão superior a tensão de tração que ele suporta motivando o aparecimento de fissuras na estrutura. A Figura 3 demonstra as fissuras no tabuleiro ocasionadas por retração.

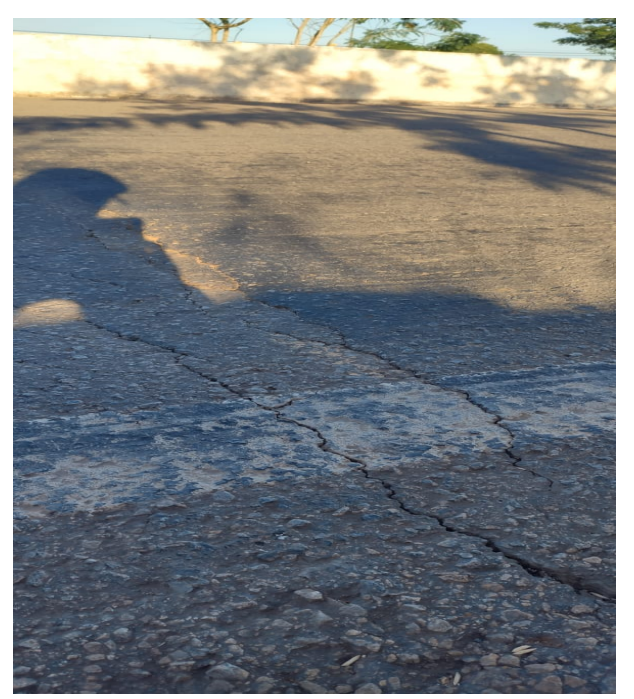

Figura 3. Fissuras no encontro com o pavimento.

\subsection{Inexistência de Aparelho de apoio}

O uso de EPS como apoio das longarinas pode ser observado na Figura 4. Essa prática comumente adota da na época que a ponte foi construída, entretanto, este aparelho de apoio deveria ter sido trocado para Neoprene a tempos, e desta forma evitar problemas, por ser um aparelho de apoio mais adequado para cargas maiores e durabilidade. Não foi realizado as devidas manutenções no material, com elevada presença de mofo, acúmulo de dejetos, sendo necessário a substituição.

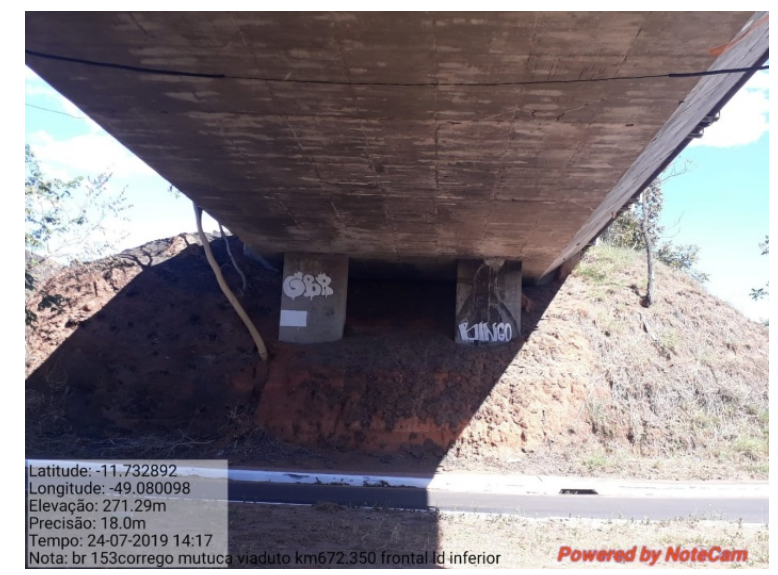

Figura 4. Não há utilização de Neoprene. 


\subsection{Pilares}

Desagregação do concreto consiste na desintegração do concreto, com este perdendo sua propriedade de aglomerante. (Souza e Ripper, 1998) entendem a desagregação do concreto, como a separação física do mesmo em fatias, de modo que a estrutura acaba por perder a capacidade resistente a esforços na região desagregada.

(Cánovas, 1988) afirma que os componentes do concreto perdem sua coesão, reduzindo significantemente a resistência mecânica. Vários são os fatores que podem ser causadores da desagregação: fissuração, movimentação das formas, corrosão do concreto, ataques biológicos e o fenômeno da calcinação que consiste na perda de resistência e mudança de cor do concreto, que ocorre quando ele se encontra na presença de fogo e começa a se desintegrar em uma temperatura próxima à $600^{\circ} \mathrm{C}$.

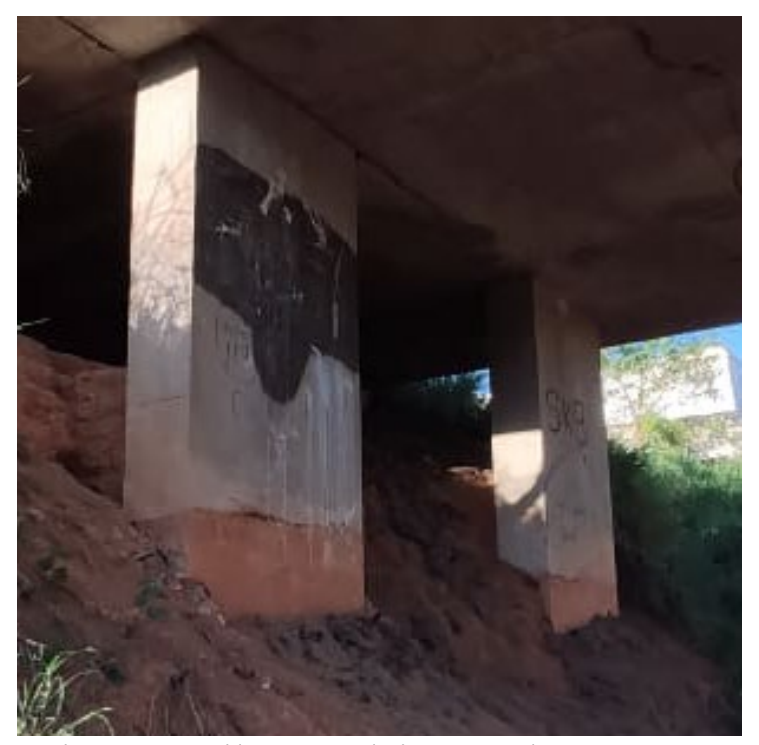

Figura 5. Pilares Calcinação do concreto.

\section{CONCLUSIONES}

Foi verificado que a ponte estudada, através de inspeções visuais apresentou manifestações patológicas comuns quando se tem a falta de manutenção e inspeção. As inspeções são fundamentais, pois elas permitem compreender o estado em que a estruturas se encontra e desta forma propor manutenções, reparos ou até mesmo reforço. Entretanto, devido esta pesquisa ter realizado apenas inspeção visual não se pode chegar a dados conclusivos e propor adequações a ponte.

O ideal é com base nesses resultados realizar uma inspeção especial e assim realizar estudos mais detalhados, uso de equipamentos, ensaios não destrutivos e destrutivos, que poderão apresentar o nível de degradação, oxidação das armaduras e resistência do concreto atual. As manifestações patológicas se não forem tratadas poderão ocasionar danos maiores a ponte, comprometendo ainda mais a sua vida útil a longo prazo. 


\section{REFERENCIAS}

ABNT - ASSOCIAÇÃO BRASILEIRA DE NORMAS TÉCNICAS. NBR 9452: Inspeção de pontes, viadutos e passarelas de concreto - Procedimento. Rio de Janeiro, 2019.

BRASIL. Departamento Nacional de Infraestrutura de Transportes - DNIT. Manual de inspeção depontes rodoviárias, 2. ed. Rio de Janeiro, 2004.

FELIX, E. F. et al. Análise da vida útil de serviço de estruturas de concreto armado sujeitas àcorrosão: uma abordagem mecânico-probabilística. In: Congreso CONPAT 2019, Tuxtla Gutiérrez,Chiapas. 2019.

FÉLIX, Emerson Felipe et al. Avaliação da durabilidade de uma viga de concreto armado sujeita àreação álcali-agregado. In: XIV CONGRESO LATINO-AMERICANO DE PATOLOGÍA DE CONSTRUCCIÓN YXVI CONGRESO DE CONTROL DE CALIDAD EN LA CONSTRUCCIÓN. Anais, 2017.

CÁnovas, M. F. Patologia e Terapia do Concreto Armado. 1 Ed. Tradução de M. C. Marcondes; C. W. F. dos Santos; B. Cannabrava. São Paulo: Ed. Pini, 1988. 522 p. 


\section{ANEXO I}

Modelo de ficha de inspeção rotineira parte 3

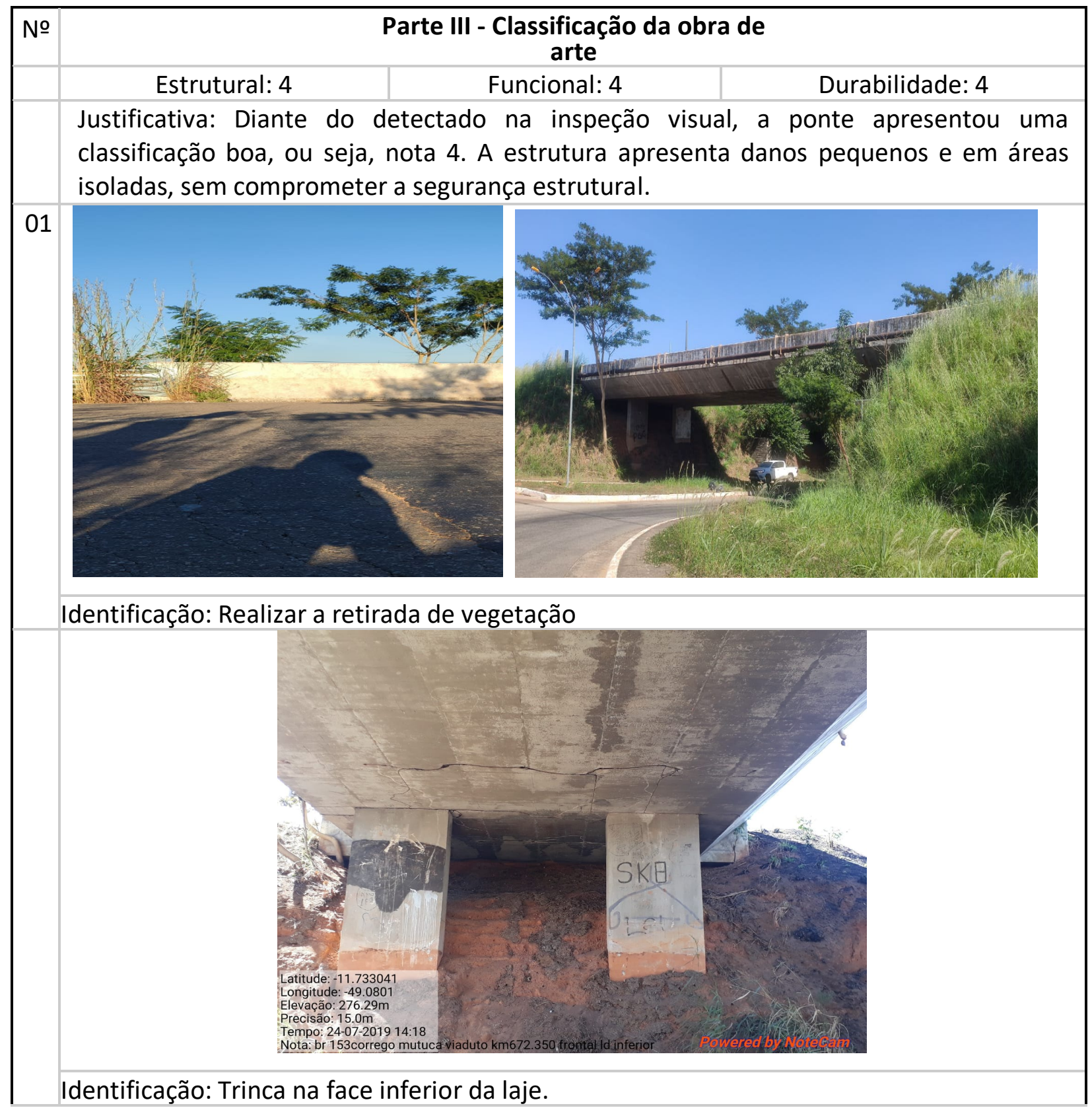




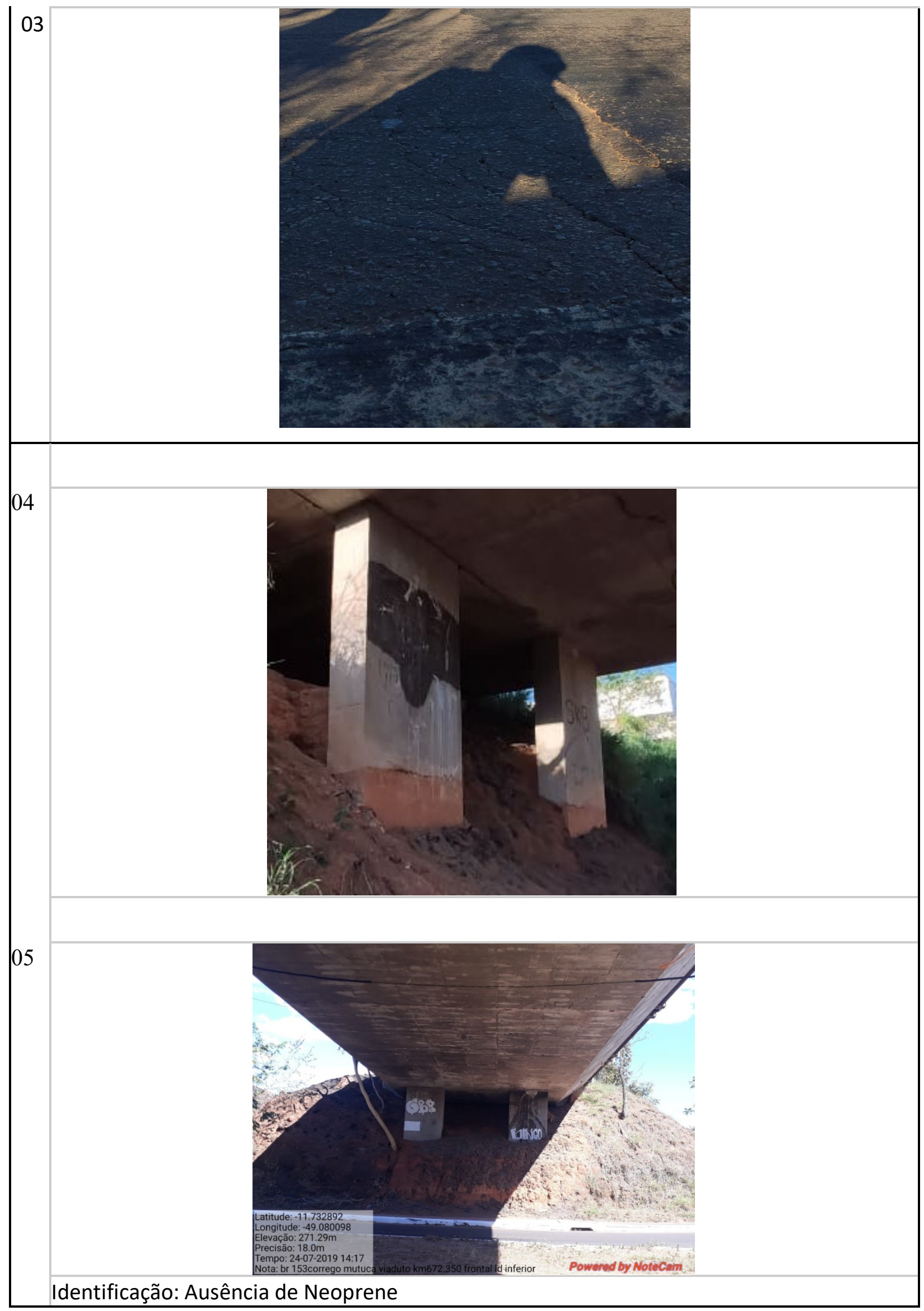

